\title{
LA SOCIOLOGÍA DE GEORG SIMMEL Y EL 'CAPITAL SOCIAL': LA CONFIANZA COMO FUERZA SOCIALIZADORA
}

\section{GEORG SIMMEL'S SOCIOLOGY AND 'SOCIAL CAPITAL': TRUST AS A SOCIALIZING FORCE}

\author{
Carolina Ovares Sánchez*
}

\begin{abstract}
Fecha de aceptación: 8 de noviembre de 2017 - Fecha de aceptación: 30 de mayo de 2018
\end{abstract}
\begin{abstract}
Resumen
La sociología de Simmel constituye uno de los orígenes teóricos de la noción de 'capital social'. Lo anterior se concluye al analizar su investigación social, a partir de las formas y contenidos de los procesos de interacción social y el papel de la confianza en la sociedad como fuerza socializadora. Concluimos que Simmel contribuye de manera significativa a la conceptualización de 'capital social'. La necesidad de lazos informales y la confianza como garantía para el mantenimiento de una sociedad y sus instituciones sociales es una constante en la sociología, desde sus inicios como disciplina. En este artículo se analizará y mostrará la contribución de Georg Simmel a las tesis sobre el capital social, desde su conceptualización de la confianza, como una de las fuerzas que configuran a la sociedad, la cual es base para el capital social. Concepto que sigue siendo un punto de referencia clave en las ciencias sociales. Palabras claves: G. Simmel; Capital social; Sociología; Confianza; Teoría social.
\end{abstract}

\begin{abstract}
Simmel's sociology constitutes one of the theoretical roots of the notion of 'social capital'. That is inferred by analyzing his social inquiry, based on the forms and contents of social interaction processes and the role of trust, as a socializing force, in society. We concluded that his contribution to the sociological conceptualization of this notion is significant. The necessity of informal ties and trust, as a guarantee for the establishment and maintenance of society, has been a constant in sociology since its origins. This article will analyze Georg Simmel's contribution, to the basis for social capital, from his approach of trust as one of the forces that shape society. This concept remains a key reference in social science.
\end{abstract} Key Words: G. Simmel; Social capital; Sociology; Trust; Social theory.

\footnotetext{
Universidad de Costa Rica, Abogada y socióloga; Maestranda Facultad Latinoamericana de Ciencias Sociales, Sede Argentina, carolinaovares@gmail.com
} 
"La confianza es una de las fuerzas sintéticas más importantes dentro de la sociedad"

\section{Introducción a la noción de 'capital social'}

En este artículo se analizará la influencia de la teorización sobre la confianza como fuerza socializadora en la sociología de Georg Simmel $^{2}$, siendo aquella uno de los determinantes para que surja el 'capital social'.

El término 'capital social' ha sido empleado como etiqueta y como un término sombrilla-genérico para explicar variopintos fenómenos. Se ha conceptualizado como una especie de 'entidad', que es medible, en relación a personas, grupos, organizaciones, comunidades, países y regiones. Es entendido como 'algo que está ahî', como variable independiente, por ejemplo, en la creación de capital humano (habilidades, conocimiento y experiencia), instituciones democráticas más eficientes, la reducción del crimen, acceso a mejor educación y empleo, movilidad social, erradicación de la pobreza, entre otros conceptos asociados. No obstante, su uso ha sido tan diverso que ha evolucionado hasta transformarse en una especie de panacea de las enfermedades que afectan a las sociedades (Portes, 1999).

El concepto de 'capital social' tiene una historia que se remonta al siglo XIX como una referencia al valor de las redes sociales. Este ha tenido una recepción y crecimiento muy importante, iniciando desde la década de los años 80 del siglo pasado 3 con las obras del sociólogo Pierre Bourdieu ${ }^{4}$ y el economista Glenn C. Loury y se popularizó por el sociólogo James Coleman ${ }^{5}$ y, particularmente, por el politólogo Robert Putnam ${ }^{6}$ durante los años noventa.

$1 \quad$ Frase obtenida de su obra Sociología (Simmel, 1986, p. 366)

2 Nació en Berlín el 1 de marzo de 1858, dentro de una familia de origen judío y posteriormente de confesión protestante murió el 26 de setiembre de 1918 de cáncer en el hígado. En 1879 ingresa en la Universidad de Berlín, donde estudia historia, filosofía, psicología de los pueblos, historia del arte e italiano antiguo.

3 Scrivens y Smith (2013) señalan un incremento de los documentos en la base de JSTOR, que contienen la frase "capital social'. Sólo cuatro referencias en 1971-1980 y 13 en 1981-1990. Sin embargo, se volvió mucho más generalizado en años posteriores, con 210 referencias entre 1991-2000, y 587 en el período entre 2001-2010 (basado en una búsqueda realizada el 30 de mayo de 2012).

$4 \quad \mathrm{Al}$ " the aggregate of the actual or potential resources which are linked to possession of a durable network of more or less institutionalized relationships of mutual acquaintance and recognition-or in other words, to membership in a groupwhich provides each of its members with the backing of the collectively owned capital, a "credential" which entitles them to credit, in the various senses of the word" ["agregado de los recursos reales o potenciales que se vinculan con la posesión de una red duradera de relaciones más o menos institucionalizadas de conocimiento o reconocimiento mutuo - o en otras palabras, para ser miembro de un grupo- que proporciona a cada uno de sus miembros el respaldo del capital de propiedad colectiva, una "credencial" que les da derecho a crédito, en los diversos sentidos de la palabra] (Bourdieu, 1986, p.21), lo definió como 'capital social'. Para explicar problemas de estratificación, teorizó sobre el manteamiento de las relaciones de poder y la jerarquía en las sociedades. La pertenencia a redes homogéneas, basadas en la clase social, permiten a sus miembros tener acceso a recursos (v.g. estatus y poder, información, influencia, oportunidades, asistencia financiera), que los mantiene en esa posición en la estructura social.

5 Coleman, desde el campo de la educación, se centró en la capacidad de las redes sociales para generar resultados positivos para sus miembros. Concluyó que el factor que diferencia el desempeño entre estudiantes de escuelas católicas sobre los de escuelas estatales, fue el alto grado de apoyo que recibieron de sus familias y las comunidades, y las estrechas relaciones entre los padres y las escuelas. Coleman, al igual que Bourdieu, veía el capital social como un recurso de los individuos, pero adoptó una visión más amplia y optimista al ver aspectos positivos de la capacidad de las redes sociales para generar resultados para sus miembros (Portes, 1998).

6 El trabajo de Putnam ha sido el más influyente, tanto en el ámbito académico, como en el de formulación de políticas públicas. Se enfoca en la idea del impacto de las redes, el compromiso cívico y las normas de reciprocidad y su relación con el desarrollo económico. Ver Putnam, Leonardi y Nanetti (1993) y Putnam (1999). 
Los enfoques de estos autores fueron disimiles; sin embargo, una línea en común es que exploraron la importancia y el valor de las redes sociales (social networks). La idea base es que las relaciones humanas y los vínculos entre las personas tienen un valor y son importantes para el individuo, los grupos y las comunidades, adicionalmente, pueden mejorar varios aspectos de la vida de las personas, por lo cual las relaciones y los contactos sociales pueden afectar la productividad de individuos y grupos (Putnam, 1999).

\section{Criterios de distinción en la literatura: no uno, sino varios 'capital social'}

Mucho se ha teorizado y conceptualizado sobre esta noción de 'capital social' y diversas investigaciones empíricas buscan medirlo, pero: ¿qué se está midiendo exactamente?, ¿cómo? y ¿por qué?, o en otras palabras, ¿cuáles son las tesis teóricas detrás del uso del término 'capital social? Si bien, el objetivo aquí no es realizar una historia conceptual del término ${ }^{7}$, ni promover una definición en particular, si es pertinente una síntesis sobre su uso, para mostrar así el aporte teórico de Georg Simmel al respecto.

El capital social ha sido conceptualizado de muchas maneras: como un constructo socioestructural y psicológico, como un fenómeno micro y macro, como una metáfora y también como un conjunto de recursos concretos. En otras palabras, por 'capital social' se denomina a las características específicas del entorno social, el cual es muy diverso, pero que puede facilitar la cooperación de las personas (Parts, 2013) .

Se pueden identificar cuatro características y hechos en la sociedad, que han sido categorizados con el término 'capital social', estas son: i) las relaciones personales; ii) el apoyo de las redes sociales; iii) el compromiso cívico; y iv) la confianza y las normas de cooperación.

Además de estas descripciones de los fenómenos en la realidad que denominamos por 'capital social', se le han asignado funciones en una variedad de contextos: 1) como fuente de control social, 2) como fuente de apoyo familiar y 3) como fuente de beneficios a través de las redes, incluyendo resolver problemas de acción colectiva.

A pesar de las diferencias de tesis sobre el 'capital social' (i.e. el sentido del término), rescatamos la idea de que hay ciertas relaciones sociales, vínculos e interacciones sociales que tienden a crear normas, instituciones o formas de organización que promueven la confianza y la cooperación y coordinación entre las personas, en las comunidades y/o en la sociedad en su conjunto. Debido a que los seres humanos confían y logran coordinar y cooperar es que pueden resolver problemas de acción colectiva. Hay aspectos estructurales que facilitan la interacción social y aspectos cognoscitivos o más psicológicos, que predisponen a la personas a actuar de una manera socialmente beneficiosa (Parts, 2013). A toda esta situación se le denomina 'capital social'.

En cualquier caso, es importante destacar que estos autores consideran que el acceso de los individuos a los recursos (i.e. capital social) depende de su participación en alguna forma de relación social (Herreros, 2004) y que al relacionarse las personas y generarse instituciones, se generan esos recursos, y dentro de esos recursos también hay normas e instituciones.

$7 \quad$ Para un análisis historiográfico de las tesis sobre el 'capital social' ver Portes (1999), quien estudia los orígenes y definiciones del capital social en los escritos de Bourdieu, Loury y Coleman, entre otros autores; también Ferragina (2010), Adler y Kwon (2002) y Ostrom y Ahn (2009 y 2013).

8 El capital social, en su sentido más amplio, se refiere a la coherencia social y cultural interna de la sociedad, la confianza, las normas y los valores que rigen las interacciones entre las personas y las redes e instituciones en las que están insertas (Parts, 2009). Como un atributo de una sociedad, el capital social puede entenderse como una característica específica del entorno social que facilita la cooperación de las personas. "The key idea of this argument is that communities can provide more effective and less costly solutions to various principal-agent and collective goods problems than can markets or government interventions" [La idea clave de este argumento, es que las comunidades pueden proporcionar soluciones más eficaces y menos costosas, a los diversos problemas de acción colectiva, que los mercados o las intervenciones gubernamentales] (Parts, 2013, p.3) 


\section{La sociología clásica y el capital social}

Cabe preguntarse si el término incorpora alguna idea realmente nueva para los sociólogos. Dado que afirmar que la intervención y participación en grupos pueden tener consecuencias para el individuo y la comunidad, ya la había realizado Durkheim en su tesis sobre la relación entre la vida grupal y la anomia.

Por lo cual, parece ser que la expresión 'capital social' responde a una intuición presente desde los comienzos mismos de la disciplina sociológica (Ferragina, 2010). Las raíces del mismo se pueden retrotraer al debate sobre la relación entre la confianza, redes sociales y desarrollo de las sociedades modernas industriales (Ferragina, 2010). Por ejemplo, el ensayo de Georg Simmel, La metrópolis y la vida mental (1903), explora el dilema entre la solidaridad comunitaria y la libertad individual.

La idea de que la confianza social ${ }^{9}$ y las redes sociales formales e informales tenían algún tipo de asociación, estaba ya presente en la teoría sociológica clásica - por ejemplo Durkheim y su idea de Solidaridad Orgánica y Mecánica o en Ferdinand Tönnies y sus categorías de análisis de Comunidad y Sociedad (Gemeinschaft y Gesellschaft ${ }^{10}$ ).

Ahora bien, ¿cómo se relaciona la idea de que el capital social incluye un elemento de relación social (por ejemplo, vínculos de redes sociales concretos) y un componente de recursos o beneficios (por ejemplo, confianza) en el actor individual o en el nivel colectivo ${ }^{11}$ y la teoría sociológica de Simmel? Se estudiará al pensador berlinés, ya que coloca a la confianza -base para el capital social- como una de las fuerzas que configuran la sociedad. En su sociología, da cuenta de los procesos que, realizándose en definitiva en los individuos, condicionan la sociabilidad, no como causas antecedentes en el tiempo, sino como procesos inherentes a la síntesis que -resumiendo- llamamos sociedad (Simmel, 1986).

\section{Epistemología de Georg Simmel}

En las ideas de Simmel, la existencia de cada individuo es singular. Es decir, las personas en su individualidad y singularidad, somos portadoras concretas e inmediatas de toda realidad histórica. Poseemos una "individualidad única de nuestro propio yo, que, como dibujado por líneas ideales, rodea nuestra realidad perceptible" (Simmel, 1986, p.44).

Por lo tanto, "uno podría sostener que sólo las partes materiales singulares [los individuos] serían la verdadera 'realidad', mientras que sus movimientos y modificaciones mutuamente causados, por ser

9 La dimensión social de la confianza capta la idea de que las relaciones sociales son fomentadas y estimuladas por un ambiente en el que las personas ciudadanas confían unas en otras, confían en sus instituciones y participan activamente en el debate político (Ferragina, 2013).

10 La distinción de Putnam (1993) entre el capital social vínculo (bonding) y capital social puente o conectivo (bridging) se basó en las categorías de Tönnies de Gemeinschaft y Gessellschaft. Esto permite reflexionar sobre una importante diferencia: la fraternidad entre iguales o la fraternidad entre diferentes, lo que trae consecuencias, por ejemplo en las actitudes ante la inmigración en comparación en las actitudes ante los impuestos o hacia la educación y la sanidad públicas (Ferragina, 2013).

11 La mayoría de estudios sobre el capital social se enfoca en las consecuencias positivas de la sociabilidad, no obstante la existencia de vínculos, de normas de coordinación y de cooperación también puede tener efectos negativos en la sociedad y en las personas. La cohesión social puede ser necesaria, para mantenernos unidos y lograr metas en común, pero también es una forma en que las organizaciones criminales sean exitosas, las redes y vínculos creados dentro de una organización criminal aumentan el nivel de capital social, pero tienen un efecto negativo en la vida social de una nación/comunidad (Ferragina, 2013). Redes comunitarias, el control social y las sanciones colectivas pueden conllevar a un sentimiento extremo de pertenencia a un grupo, lo que puede generar fisuras entre distintos grupos sociales y generar un clima de violencia y confrontación. Además, de exclusión de los extraños, reclamos excesivos a los integrantes del grupo, restricciones a la libertad individual y normas niveladoras hacia abajo (Portes, 1999). En otras palabras, los grupos pueden fomentar los lazos entre los participantes, pero también construir muros con respecto a los extraños (outsiders) y miembros de otros grupos. 
algo nunca asible, en cierto modo sólo serían realidades de segundo grado" (Simmel, 2002, pp.33-34). Se podría afirmar que, "palpando lo tocable, sólo encontraríamos individuos, y entre ellos nada más que espacio vacío" (Simmel, 2002, p.34).

Sin embargo, de esto no se deduce - y es lo que Simmel quiere resaltar- que los individuos sean los únicos que tienen 'existencia' y que la sociedad es una unidad, producto de la suma de los intereses y fines de las personas.

Las tesis sociológicas del autor, para fundamentar lo anterior, consisten en:

i. La realidad social se explica a partir del individuo. "Se puede insistir en que las auténticas realidades siempre serían únicamente los individuos humanos. Mas no se gana nada con esto" (Simmel, 2002, pp.33-34).

ii. Los individuos están vinculados por influencias y determinaciones recíprocas que se dan entre ellos -instintos y fines- a esta vinculación la denomina acción recíproca.

iii. La unidad de estas acciones se denomina 'sociedad'.

iv. 'Sociedad' es "sólo el nombre de un entorno de individuos que están ligados entre ellos por los efectos de estas relaciones recíprocas y que por esto se definen como una unidad, lo mismo que se define como unidad un sistema de masas corporales que se determinan totalmente en su comportamiento por su influencia recíproca" (Simmel, 2002, pp.33-34).

v. La sociedad es algo funcional que los individuos hacen y sufren, y según su carácter fundamental no habría que hablar de sociedad, sino de socialización (Simmel, 2002, p.34).

Ahora bien, partiendo de lo anterior, ¿cómo explicar que las personas se relacionan entre ellas? y ¿cómo es que se relacionan entre ellas?; ¿cómo explicar - por ejemplo- el secreto, la amistad, el amor o la condición de extranjería, la lucha, la subordinación, la libertad y la dominación? Simmel responde a estas interrogantes indicando que las personas tienen instintos y fines que las llevan a relacionarse con los otros seres humanos,

Los instintos eróticos, los intereses materiales, los impulsos religiosos, los fines de la defensa y del ataque, el juego y el trabajo lucrativo, la prestación de ayuda, la enseñanza e incontables otros, hacen que el ser humano entre con los otros en una relación de estar juntos, de actuar unos para otros, con otros, contra otros, en una correlación de circunstancias, es decir que ejerce efectos sobre otros y sufre efectos por parte de éstos (Simmel, 2002, pp. 33-34).

A esta situación Simmel la denominó acción recíproca. La persona entra en relación con otro o con otros y se producen acciones recíprocas, se generan por determinados instintos o para determinados fines,

La existencia de estas acciones recíprocas significa que los portadores individuales de aquellos instintos y fines, que los movieron a unirse, se han convertido en una unidad, en una sociedad. Pues unidad en sentido empírico no es más que una acción recíproca de elementos: un cuerpo orgánico es una unidad, porque sus órganos se encuentran en un cambio mutuo de energías, mucho más íntimo que con ningún ser exterior (Simmel, 1986, pp.15-16).

Simmel $(2002,1986)$ parte del supuesto de que el individuo está determinado en toda su esencia y todas sus manifestaciones por vivir bajo el efecto recíproco del actuar con otros seres humanos, por la circunstancia de vivir en acción recíproca con otros. Por lo cual, la sociedad -como se deduce de la cita previa- no es una sustancia, "nada concreto en sí mismo, sino un acontecer, la función del recibir y efectuar del destino y de la configuración de uno respecto a otro" (Simmel, 2002, pp. 33-34).

Asimismo, la unidad de estas acciones reciprocas - la sociedad, se da por la existencia de condiciones que la posibilitan, las cuales existen 'a priori'. Al preguntarse el pensador berlinés cómo es posible la sociedad (análogamente a la pregunta de Kant ¿Cómo es posible la naturaleza?), busca dar cuenta de estos a priori. 
Para entender a qué se refiere Simmel cuando señala la existencia de los 'a priori', se debe explicar cómo se conoce, desde la perspectiva de este pensador. En atención a sus influencias neokantianas, este sociólogo germano considera que la persona conoce el mundo según un conjunto de categorías apriorísticas. Parte del supuesto que, "nuestro pensamiento siempre sintetiza los hechos dados a configuraciones, como objetos científicos, en una manera que en la realidad inmediata no encuentra reflejo alguno" (Simmel, 2002, pp. 25-26).

Lo anterior presupone la distinción entre contenido y forma (dada sus bases kantianas). El autor llama contenido a:

Todo aquello que en los individuos, en los lugares inmediatamente concretos de toda realidad histórica está presente como impulso, interés, finalidad, inclinación, estado psíquico y movimiento, de tal manera que a partir de ello o en ello se produce el efecto sobre otros y se recibe estos efectos (Simmel, 2002, p. 78).

Los contenidos son aspectos de la existencia, los cuales se determinan por sí mismos, pero "as such contain neither structure nor the possibility of being apprehended by us in their immediacy" [no contienen ninguna estructura ni la posibilidad de ser aprehendidos por nosotros en su inmediatez]" (Levine en Simmel, 1971, p.6). Por eso, se requieren las formas, las cuales son "synthesizing principles which select elements from the raw stuff of experience and shape them into determinate unities" [principios sintetizadores que seleccionan elementos del material de la experiencia y que los moldean dentro de determinadas unidades ${ }^{12}$ ] (Levine en Simmel, 1971, p.6). Pareciera ser que los conceptos abstractos, para ordenar el mundo, están en nuestra cabeza y es nuestra cabeza - o sea nosotros mismos- quienes ordenamos estos hechos desordenados.

No obstante, las 'formas' también son inherentes a la realidad ${ }^{13}$. Para Simmel la realidad no es posible abarcarla totalmente -en su integridad inmediata- tampoco desde las ciencias, por lo cual esta se aprehende, "desde varios puntos de vista separados, creando así una pluralidad de objetos científicos independientes uno de otros" (1986, p.33). Así es como explica la existencia de distintas disciplinas que estudian problemas sociales, como la sociología.

El mundo real está compuesto de innumerables acontecimientos, acciones, interacciones, impulsos, intereses, finalidades, inclinaciones, estados psíquicos y movimientos -estos son los contenidos- la materia de socialización. Y para orientarse en el laberinto de la realidad, Simmel indica que las personas la ordenan mediante su reducción a modelos o formas, de esta manera la persona se enfrenta a un número limitado de formas, en lugar de a un conjunto confuso de acontecimientos específicos (Levine, en Simmel, 1971); la sociología - en Simmel- es un método para ordenar estos contenidos ${ }^{14}$.

12 Donald N. Levine al introducir la selección de textos de Simmel, denominada On Individuality and Social Forms, señala que "forms are identical with Kant's a priori categories of cognition; but they differ from the latter in two important respects. They inform not only the cognitive realm, but any and all dimensions of human experience. And they are not fixed and immutable, but emerge, develop, and perhaps disappear over time. Forms emerge to shape contents when the undifferentiated unity of immediate experience is ruptured by some sort of stress" [las formas son idénticas a las categorías cognitivas a priori de Kant; aunque difieren de estas últimas en dos importantes aspectos. Aquellas informan no sólo sobre el dominio de lo cognitivo, sino incluso de cualquiera y de todas las dimensiones de la experiencia humana. Y no son fijas e inmutables, sino que emergen, se desarrollan y quizá desaparecen con el transcurso del tiempo. Las formas emergen moldeando los contenidos cuando, por una suerte de tensión, se rompe la unidad indiferenciada de la experiencia inmediata] (Simmel, 1971).

13 La discusión del estatus ontológico de las formas no se detallará en esta monografía, ya que excedería su objetivo, para una revisión del tema se recomienda ver el artículo de Tenbruk (1965), denominado Formal Sociology.

14 Surge la cuestión de qué es lo que hace la sociología para que no sea sólo un rejuntado de otras ciencias sociales, ¿por qué la sociología va a generar conocimientos distintos a las otras ciencias ya existentes? La respuesta dada por Simmel es que, "lo que la diferencia [a la Sociología] de las demás ciencias histórico-sociales no es, pues, su objeto, sino el modo de considerarlo, la abstracción particular que en ella se lleva a cabo" (Simmel, 1986:20). Por lo cual, la sociología no contiene ningún objeto que no fuera tratado ya por alguna de las ciencias existentes. En consecuencia, ésta lo que representa es 
Estas 'formas', en un principio responden a los fines de conservación y fomento de la vida. Las personas, gracias a ellas, elaboran el material de la vida que hay que obtener del mundo mediante la fuerza de la inteligencia, la voluntad y el impulso configurador.

En este estadio, el conocer se presta a esfuerzos prácticos. No obstante, para Simmel hay una evolución de las formas, en cómo entendemos al mundo, hasta llegar a un punto de automatización, (ejemplificado con la ciencia y el arte). En la siguiente cita extensa de su obra Cuestiones fundamentales de Sociología, explica el proceso de surgimiento del arte, lo que asimila también a la explicación de la gestación de la ciencia,

\begin{abstract}
Aquella, [el arte] se ha convertido en un valor propio, que escoge por sí misma sus objetos, los configura según sus necesidades internas y no pregunta más allá de su propia perfección. Además, la configuración de realidades perceptibles e imperceptibles según formas espaciales cerradas, ritmo y sonido, significado y organización, surgió sin duda originariamente de las exigencias de nuestra práctica. Pero cuando estas formas se convierten en fines en sí mismos y ejercen su efecto por su propia fuerza y su propia ley, selectivas y creativas desde ellas mismas y no en función de su entrelazamiento con la vida, entonces ha surgido el arte, por completo separado de la vida y extrayendo de ésta sólo lo que le sirve y que por medio de él se genera en cierto modo por segunda vez, aunque las formas en que lo hace y en que consiste, por decirlo así, se han generado dentro de las exigencias y la dinámica de la vida (Simmel, 2002, pp.79-80).
\end{abstract}

No se pueden captar los contenidos, por eso el ser humano se atiene a las formas -estructuraciones constitutivas y permanentes- de los fenómenos de la misma naturaleza, pero que en innumerables ocasiones se manifiestan bajo condiciones particulares (Tenbruk, 1965). La sociedad, como el conjunto de acciones recíprocas, se estudia a través de las formas de socialización ${ }^{15}$.

¿Cómo estudiamos esas formas de socialización? Se construyen configuraciones coherentes a partir de la realidad y se descubren leyes y evoluciones en ellas; estas configuraciones no existen en absoluto como entes aislados experimentables (Simmel, 2002, p.35), estas construcciones se dan por medio de un proceso de abstracción ${ }^{16}$ de la realidad. La siguiente cita del pensador berlinés detalla este proceso:

toda ciencia se funda en una abstracción, por cuanto considera en uno de sus aspectos y desde el punto de vista de un concepto en cada caso diferente, la totalidad de una cosa, que no puede ser abarcada por ninguna ciencia. Ante la totalidad de la cosa y de las cosas, crece cada ciencia por división de aquella totalidad en diversas cualidades y funciones, una vez que se ha hallado el concepto que separa estas últimas, y permite comprobar metódicamente su presencia en las cosas reales (Simmel, 1986, p.14).

El proceso de abstracción debe ser entendido en el sentido de extraer o sacar de la realidad algo que no es directamente observable, "cualquier ciencia extrae de la totalidad o de la inmediatez experimentada de los fenómenos una serie o un lado guiándose en cada caso por un concepto determinado" (Simmel, 2002, p.35).

En la sociología se abstraen las formas de socialización, gracias al concepto de acción recíproca. La sociología "descompone las existencias individuales y las vuelve a resumir nuevamente según un concepto que sólo es propio a ella" (Simmel, 2002, p.35) ¿Cuál es este concepto que le es propio a ella?

un método científico nuevo, que precisamente, por su aplicabilidad al conjunto de los problemas no es una ciencia con contenido propio (Simmel, 2002).

15 Estas se estructuran de manera tal que aunque cambien de contenido no de forma, de ahí que se puede afirmar que lo que después se llamó rol, norma, estatus es similar a las formas de socialización de Simmel.

16 La teorización de las formas en Simmel se asemeja a los tipos ideales de Weber (Tenbruk, 1965). Ya que, el proceso de abstracción no debe ser entendido como un proceso de generalización de las formas, donde se rechazan los elementos no comunes para lograr obtener las características generales; y las formas no deben ser entendidas como un concepto obtenido sólo por medio de un proceso empírico-inductivo (Tenbruk, 1965). 
La respuesta obvia parece ser la sociedad ${ }^{17}$, pero no es así, ya que Simmel la define como aquella que existe allí donde varios individuos entran en acción recíproca" (1986, p.14), por lo cual, la respuesta es esta última, la acción recíproca.

Ahora bien, volviendo a la distinción entre contenido y forma, ya se observó que el autor denomina 'contenido' o 'materia de la socialización' “a cuanto existan en los individuos (portadores concretos e inmediatos de toda realidad histórica), capaz de originar la acción sobre otros o la recepción de sus influencias; 1lámese instinto, interés, fin, inclinación, estado o movimiento psíquico" (Simmel, 1986, pp. 15-16). Estos contenidos no son todavía 'sociales', ya que "la socialización sólo se presenta cuando la coexistencia aislada de los individuos adopta formas determinadas de cooperación y colaboración que caen bajo el concepto general de la acción recíproca" (Simmel, 1986, p.16).

¿Qué elementos generales y a priori han de servir de fundamento, qué supuestos han de actuar para que los procesos singulares concretos, de la consciencia del individuo sean verdaderos procesos de socialización? Una de las condiciones que actúan a priori es la conciencia de socializarse o estar socializado en los procesos de acción recíproca (Simmel, 1986, p.43). La acontece por medio de un proceso de conciencia, que pone en relación al ser individual de cada elemento con el otro. En el caso de las acciones recíprocas están compuestas por elementos conscientes que practican una actividad sintética, que se realiza sin más y no necesita de ningún contemplador (Simmel, 1986, p.39).

Las relaciones sociales se realizan en las cosas, en las almas individuales, y esta relación es una síntesis. La siguiente cita ilustra lo anteriormente dicho:

La conciencia de constituir una unidad con los demás es aquí, de hecho, la unidad misma cuya explicación se busca. Esto, por una parte, no supone, naturalmente, la conciencia abstracta del concepto de unidad, sino, las incontables relaciones individuales, el sentir y saber que uno determina a otros y es, a su vez, determinado por ellos (...) La sociedad, empero, es la unidad objetiva, no necesitada de contemplador alguno, distinto de ella (Simmel, 1986, p.40).

\section{La confianza como fuerza socializadora}

¿Cuál es el problema o qué quiere explicar Simmel? Quiere entender a la sociedad que -como ya se vio- son las acciones recíprocas que se pueden conocer bajo ciertas formas de socialización. Simmel buscaba comprender, analizar y estudiar las formas de socialización, cuya categoría-unidad de análisis es la acción recíproca, este es el concepto sociológico fundamental. Por lo cual, la tarea de la sociología ${ }^{18}$ es la descripción y explicación de las formas de este efecto recíproco.

Para el pensador germano, hay fuerzas socializadoras por excelencia, que configuran la sociedad, o sea, las acciones recíprocas estudiadas desde la sociología en formas de socialización. Estas son

17 Para Simmel el concepto de sociedad tiene dos significaciones. "Por un lado, sociedad es el complejo de individuos socializados, el material humano socialmente conformado, que constituye toda la realidad histórica. Pero, por otro lado, la 'sociedad' es también la suma de aquellas formas de relación por medio de las cuales surge de los individuos la sociedad en su primer sentido" (1986, pp.20-21). Asimismo, indica que "cuando se trata de las ciencias sociales en el primer sentido, su objeto es todo lo que acontece en la sociedad y por ella. La ciencia social, en el segundo sentido, tiene por objeto las fuerzas, relaciones y formas, por medio de las cuales los hombres se socializan y que por tanto constituyen la 'sociedad' sensu strictissimo; lo cual no se desvirtúa por la circunstancia de que el contenido de la socialización, las modificaciones especiales de su fin e interés material, decidan a menudo, o siempre, sobre su conformación” (Simmel, 1986, pp.20-21)

18 A la sociología de Simmel se le conoce como sociología pura, tal y como él mismo la denominó, "si se puede decir que la sociedad es el efecto recíproco de la acción de los individuos, entonces la descripción de las formas de este efecto recíproco sería la tarea de la ciencia de la sociedad en el sentido más estricto y auténtico de 'sociedad'. [...] Esta investigación -se la podría llamar 'sociología pura'- extrae de los fenómenos el elemento de la socialización desprendiéndolo inductiva y psicológicamente de la multiplicidad de sus contenidos y fines que por sí mismos aún no son sociales, tal como la gramática separa el lenguaje de las formas puras de los contenidos en las que aquéllas son activas (Simmel, 2002, p.50) 
la concordia, la armonía y la cooperación. Estas fuerzas organizadoras están fijas y parecen dar a la sociedad el carácter de tal (Simmel, 1986, p. 365) ${ }^{19}$.

Junto con las anteriores fuerzas, se incluye la confianza. Se concluye lo anterior a partir de diversos pasajes en la obra de Simmel, Sociología y en la Filosofía del Dinero. Ahí, indica que la confianza es una de las fuerzas sintéticas más importantes que actúan en la sociedad (Simmel, 1986, p. 366).

Para el agente/actor individual es "una hipótesis sobre la conducta futura del otro, hipótesis que ofrece seguridad suficiente para fundar en ella una actividad práctica” (Simmel,1986, pp. 366-367). Para engendrar la confianza, por ejemplo,

el comerciante que vende a otro trigo o petróleo, solo necesita saber si este tiene solvencia para responder del importe; pero si toma a otro como socio, ha de conocer, no solo su situación patrimonial y otras cualidades generales, sino toda su personalidad, su honradez, el grado de confianza que merece el temperamento que tiene, si es resuelto o vacilante, etc. Y sobre ese conocimiento mutuo, descansa no solo el establecimiento de la relación, sino su prosecución, las acciones comunes diarias, la distribución de funciones entre los compañeros (Simmel,1986, p. 368).

En este respecto, la confianza es una predicción y representación de los estados mentales de la otra persona, es una conjetura sobre cómo va a proceder el otro.

En otro pasaje, Simmel nos revela como la confianza se da a nivel institucional -confianza social- no sólo a nivel interpersonal. "El sentimiento de seguridad personal que ocasiona la posesión del dinero es seguramente la forma y expresión más concentradas y aguzadas [sic] de la confianza en la organización y el orden estatales y sociales" (Simmel, 1976, p.190). Por lo tanto, "trust for Simmel represents a force that works for and through individuals, but at the same time for and through human association more generally. Trust's function manifests itself at all levels of society" [la confianza para Simmel representa una fuerza que trabaja para y a través de los individuos, pero al mismo tiempo para y a través de las asociaciones humanas, más generalmente. La función de la confianza se manifiesta en todos los niveles de la sociedad] (Möllering, 2001, p.405).

Retomando lo dicho sobre el capital social en acápites previos, la confianza es un estado de expectativa favorable con respecto a las acciones e intenciones de otras personas. Ahora, este estado favorece a las redes y organizaciones sociales y por ende a la sociedad (pues facilita su cohesión y beneficia la resolución de problemas de acción colectiva). Esta línea de pensamiento ya está presente en Simmel, al señalar que "las tradiciones e instituciones, el poder de la opinión pública y el rigor de la situación de cada cual (que [en conjunto] determinan inexorablemente la conducta del individuo) se han hecho tan firmes y seguros, que basta conocer ciertas exterioridades referentes al otro, para poseer la confianza necesaria a la acción común" (Simmel,1986, p. 367) ${ }^{20}$.

¿Qué hace que un grupo humano - organización social- tenga capacidad para vivir y actuar en conjunto, para ponerse de acuerdo sobre una orientación común, un proyecto común o un destino común? La respuesta es - en parte- la confianza.

19 Simmel explica que para que la sociedad se configure se requiere procesos de condescendencia y resistencia, "para que resulte la verdadera configuración de la sociedad, es preciso que estas fuerzas socializadoras por excelencia, sean contrapesadas por la distancia, la competencia, la repulsión. Aquellas han de verse constantemente estorbadas, desequilibradas, impedidas por fuerzas individualistas irregulares, para adquirir vida y evolución, gracias a estos procesos de condescendencia y resistencia" (Simmel, 1986, p.365).

20 Simmel en el capítulo sobre "El secreto y la sociedad secreta" de su Sociología (1986) utiliza el interés del grupo (Zweckverband) como ejemplo extremo y puro de una asociación psicológicamente anónima y observa la creciente objetivación de la cultura, cuyos fenómenos consisten cada vez más en elementos impersonales y cada vez menos absorben la totalidad subjetiva del individuo (1986, p. 367). "This objectification of culture has a bearing on the constitution of confidence in that less and less personal knowledge about the other is required to have confidence" [Esta objetivación de la cultura tiene que ver con la constitución de la confianza en que se requiere un conocimiento cada vez menos personal del otro para tenerla] (Möllering, 2001, p. 406). 
Putnam (1999) indica que las organizaciones sociales tienen características que contribuyen al buen gobierno y al progreso económico. Una de las tesis de este autor es que la participación e implicación de las y los ciudadanos en asuntos que conciernen a sus grupos o comunidades influye, en algunos aspectos, al logro de ciertos objetivos de interés nacional. Esto se debe parcialmente al grado de confianza y reciprocidad que existe entre las personas, a las normas de comportamiento practicadas y al nivel de asociatividad que caracteriza a la sociedad.

El trabajo de Simmel ya contiene pensamientos cruciales sobre tales bases de confianza, en particular el reconocimiento del afecto y la confianza personal, además de la razón y la confianza del sistema/estructura (Möllering, 2001, p. 405). El pensador berlinés señala que la sociedad desaparecería sin la existencia de la fe recíproca [o confianza en otras traducciones] entre las personas (Simmel, 1976, p. 189).

En su obra Filosofía del Dinero el papel de la confianza en las relaciones sociales está presente, tal y como se expresa en la siguiente cita:

\footnotetext{
También el crédito económico contiene en muchos casos un elemento de esta fe supra teórica que se manifiesta en aquella confianza en la comunidad, en el sentido de que esta nos ha de garantizar la contrapartida de valores a cambio de los signos simbólicos por los que hemos entregado los productos de nuestro trabajo. Como hemos dicho, esto es, en gran medida una conclusión inductiva muy simple, pero, además, contiene aquel complemento de una fe social y psicológica, emparentada con la religiosa (Simmel, 1976, p.190).
}

La cita anterior resalta como Simmel percibe la confianza desde una perspectiva cuasi religiosa. Para este pensador, en los procesos de confianza se combina un conocimiento inductivo con alguna fe misteriosa e inexplicable.

En una cita al pie de su obra Sociología, Simmel da cuenta de esta forma de concebir la confianza, al hablar sobre otro tipo de confianza que no se refiere al saber o a la ignorancia, es aquella "que se designa con la calificación de fe de un hombre en otro y que entra en la categoría de la creencia religiosa. [...]. Esta confianza, este entregarse sin reparos a una persona, no se funda en experiencia ni hipótesis, sino que es una actitud primaria del alma, frente al otro" (Simmel, 1986, p. 367). No obstante, "en aquellas otras formas sociales de la confianza, por exacta e intelectualmente que aparezcan fundadas, se hallará también un resto de esta fe sentimental e incluso mística del hombre en el hombre" (Simmel, 1986, p.367).

Como se puede observar, desde una perspectiva entre la ignorancia y el conocimiento, se fundamenta lo que Simmel entiende por confianza. Esta surge a partir de un conocimiento inductivo y una especie de fe en el otro. Sin embargo, manifiesta otra fuente de la confianza en la reciprocidad y la obligación moral,

la confianza de un hombre en otro posee un valor moral tan alto como la debida correspondencia a dicha confianza; y acaso más meritorio aún, porque la confianza que se nos otorga, contiene un prejuicio casi constrictivo, y para defraudarla es preciso ser positivamente malo. En cambio, la confianza se regala; no puede solicitarse en la misma medida en que puede exigirse que se corresponda a ella, una vez otorgada (Simmel, 1986, pp. 397-398).

En síntesis, la confianza constituye un grado intermedio entre el saber acerca de otros individuos y la ignorancia respecto a ellos: "El que sabe, no necesita confiar; el que ignora, no puede siquiera confiar" (Simmel, 1986, p. 397), una fe cuasi religiosa pero también un valor moral.

\section{Conclusiones}

Una cuestión importante presente en las obras de Simmel consiste en cómo pensar la relación individuo- sociedad (característica de su época). En el sociólogo berlinés, la persona y la sociedad tienen que ser pensadas de forma única, en forma de unidad, como él mismo lo expresa y como se muestra 
en las citas expuestas en párrafos previos. Lo que busca explicar con su método son las relaciones, las interacciones de los individuos que confluyen y generan una unidad, denominada 'sociedad'.

En el pensamiento de Simmel la sociedad se estudia a partir de la forma en que los diversos fenómenos sociales se estructuran, cómo esos fenómenos aparecen a partir de las múltiples interacciones entre los individuos y de las diversas manifestaciones de convivencia entre las personas. Es decir, que las personas entran en acción recíproca.

La tesis del capital social, en la cual se afirma que cierta intervención y participación en grupos puede tener consecuencias - negativas o positivas- para la persona y la comunidad o para su grupo social (sea porque se generan normas y/o recursos) estaba ya presente en las ideas planteadas por Georg Simmel, esto es, las consecuencias positivas de la sociabilidad.

Asimismo, la confianza como un factor que permite la creación y obtención de capital social (i.e. recursos) es tratada por Simmel en su propuesta sobre las relaciones sociales y la descripción de la sociedad y la idea que la confianza tiene implicaciones para la forma en cómo se generan socialmente las relaciones y se producen intercambios. Este es uno de los cimientos de las teorías sobre el capital social y las redes sociales en la actualidad (Souto Maior Fontes, 2015).

El capital social consiste en una serie de valores, actitudes y recursos de los ciudadanos y las ciudadanas en relación con la confianza, reciprocidad y cooperación. Visto de esta manera, el capital social es un fenómeno que se refiere a las actitudes colectivas de las personas que tienen con las otras y de la forma en cómo se relacionan. Este es un asunto presente en Simmel y en sus formas de socialización, al señalar que la confianza es una de las fuerzas sintéticas de la sociedad, algo que las personas tienen en sí y que permite la socialización.

Ante las preguntas: ¿qué hace que un grupo de personas tenga capacidad para vivir y actuar en conjunto, para ponerse de acuerdo sobre una orientación común, un proyecto común o un destino común? O ¿Cómo, mediante normas de coordinación o cooperación, las personas logran objetivos en común? El abordaje del pensador berlinés sobre la confianza permite explicar -en parte- la cohesión social y la permanencia y duración de las distintas relaciones sociales.

Los autores denominados 'clásicos' en la sociología se pueden rescatar de varias formas. Una de ellas, es la histórica, esto es, realizando una síntesis de sus principales ideas dadas en el momento. Otra es intentando utilizar sus tesis y conceptos en la actualidad.

En el caso de Simmel, podemos afirmar que siguen presentes algunos de los problemas básicos que intentó resolver. Una de sus principales tesis es reconocer a los individuos como realidades sociales, es decir, aceptar que lo social surge de la persona. Debido a esto, no se debe considerar a la sociedad como una esencia que está por encima de los individuos. Empero, la interacción social tampoco consiste en la mera suma o agregación de los individuos en busca de sus propias metas.

Simmel buscaba no sólo explicar grandes acciones recíprocas como el Estado, el matrimonio, las clases sociales, sino también comprender qué es lo que sucedía en los celos, la caricia, el arte, "Los hombres se miran unos a otros, tienen celos mutuos, se escriben cartas, comen juntos, son simpáticos o no, se visten, se arreglan unos a otros" (Simmel, 1986, p.30). Quería explicar estas miles de "relaciones momentáneas o duraderas, conscientes o inconscientes, efímeras o fecundas, que se dan entre persona y persona, y de las cuales se entresacan arbitrariamente estos ejemplos, nos ligan incesantemente unos con otros" (Simmel, 1986, p.30).

Por último, otro aporte importante para la actualidad que cabe resaltar de Simmel, es que, en la sociología posterior a él, se desarrollaron teorías para describir y explicar la sociedad como una estructura social. Para eso, se han empleado los conceptos de estatus, rol, expectativas típicas, acciones típicas y normas. Algunas de estas bases se pueden encontrar en las formas de socialización desarrolladas por Simmel. Si bien, no construyó una teoría general de la forma, estos conceptos después se han utilizado para las teorías generales sobre la estructura social (Tenbruck, 1965). 


\section{Referencias}

Adler, Paul S. y Kwon Seok-Woo. (2002). “Social Capital: Prospects for a New Concept”. En, The Academy of Management Review, Vol. 27, No. 1, pp. 17-40

Bourdieu, Pierre. (1986). "The forms of capital". En Handbook of Theory and Research for the Sociology of Education. Richardson, J. (editor). Westport, CT: Greenwood, pp. 241-58.

Ferragina, Emanuele. (2010). "Social Capital and Equality: Tocqueville's Legacy: Rethinking social capital in relation with income inequalities". En, The Tocqueville Review, Vol. XXXI, n 1-2010.

Ferragina, Emanuele. (2013). "The socio-economic determinants of social capital and the mediating effect of history: Making Democracy Work revisited". En, International Journal of Comparative Sociology, 54(1) 48-73.

Ferragina, Emanuele y Arrigoni, Alessandro. (2016). "The Rise and Fall of Social Capital: Requiem for a Theory?" En, Political Studies Review, 1-13.

Herreros, Francisco. (2004). The Problem of Forming Social Capital: Why Trust? Estados Unidos: Palgrave Macmillan.

Möllering, Guido. (May 2001). "The Nature of Trust: From Georg Simmel to a Theory of Expectation, Interpretation and Suspension”. Sociology, Vol. 35, No. 2: 403-420.

Lewis. A. Coser. (1965). “Introducción”. En Georg Simmel. New Jersey Prentice-Hall , Inc.

Ostrom, Elinor y Ahn, T.K. (2009). “The meaning of social capital and its link to collective action”. En, Handbook of Social Capital, The Troika of Sociology, Political Science and Economics. UK: Edward Elgar Publishing Limited.

Ostrom, Elinor y Ahn, T.K. (2003). "Una perspectiva del capital social desde las ciencias sociales: capital social y acción colectiva”. En, Revista Mexicana de Sociología, Vol.65, n.1, pp.155-233.

Parts, Eve. (2013). "The Dynamics and Determinants of Social Capital in the European Union and Neighbouring Countries". Discussions on Estonian economic policy: Theory and practice of economic policy in the European Union, No.1. Recuperado de http://dx.doi.org/10.2139/ ssrn.2336016

Portes, Alejandro. (1999). “Capital Social: Sus orígenes y aplicaciones en la sociedad moderna”. En, De igual a igual. El desafío del Estado ante los nuevos problemas sociales, Jorge Carpio e Irene Novacovsky (Compiladores). Buenos Aires, Argentina: SIEMPRO- FLACSO - Fondo de Cultura Económica de Argentina.

Putman, Robert D., Leonardi, Robert y Nanetti, Rafaella. (1993). Making democracy work: Civic traditions in modem Italy. United Kingdom: Princeton University Press

Putman, Robert D. (1999). Bowling Alone. The collapse and revival of American community. New York: Simon\& Schuster.

Scrivens, Katherine y Smith, Conal. (2013). Four Interpretations of Social Capital: An Agenda for Measurement. OECD Statistics Working Papers, 2013/06, OECD Publishing, Paris.

Simmel, Georg. (1964) (1903). "The metropolis and mental life”. En K. H. Wolff (comp./trad.), The Sociology of Georg Simmel., p. 409-424. Nueva York: Free Press

Simmel, Georg, (1971). On individuality and social forms. Edición e introducción de Donald N. Levine. Chicago: University of Chicago Press.

Simmel, Georg. (2002). Cuestiones fundamentales de Sociología. Madrid: Gedisa.

Simmel, Georg. (1986). Sociología, 1 Estudios sobre las formas de socialización. Madrid: Alianza.

Simmel, Georg. (1976). Filosofía del Dinero. Madrid: Centro de Estudios Constitucionales.

Souto Maior Fontes, Breno Augusto. (2015). "La contribución de Simmel a la sociología reticular”. En, Estudios Sociológicos XXXIII, 99: 527- 55.1

Tenbruk, F.H. (1965). "Formal Sociology”. En Georg Simmel. New Jersey Prentice-Hall , Inc. 